\title{
The Study of a New Ceramic PZT Material $\mathrm{Pb}_{1-0.04} \mathrm{Sm}_{0.02} \mathrm{Nd}_{0.02}\left[\left(\mathrm{Zr}_{0.55}, \mathrm{Ti}_{0.45}\right)_{1-2 x}, x\left(\mathbf{Y}_{2 / 3}, \mathbf{M o}_{1 / 3}\right)\right.$, $\left.x\left(Y_{2 / 3}, N_{1 / 3}\right)\right] O_{3}$ with SEM and $X-R a y$ Diffraction
}

\author{
Oum Keltoum Kribaa ${ }^{1}$, Ahmed Boutarfaia ${ }^{2}$ \\ ${ }^{1}$ University of Biskra, Biskra, Algeria; ${ }^{2}$ University of Ouargla, Ouargla, Algeria. \\ Email: Kribaa_keltoum@yahoo.fr, aboutarfaia@yahoo.fr \\ Received August $2^{\text {nd }}, 2013$; revised September $4^{\text {th }}, 2013$; accepted September $18^{\text {th }}, 2013$ \\ Copyright (C) 2013 Oum Keltoum Kribaa, Ahmed Boutarfaia. This is an open access article distributed under the Creative Commons \\ Attribution License, which permits unrestricted use, distribution, and reproduction in any medium, provided the original work is \\ properly cited.
}

\begin{abstract}
The PZT is modified by the introduction of doping agents in A-sites and/or B-sites of perovskite structure [1]. The principal role of dopants is generally improving the properties of these materials for their adaptation to specific applications, which is the purpose of this study. Our choice fell on the mixed oxide: acceptor and donor. Five compositions with varying dopants percentage were prepared by the conventional method of thermal synthesis of mixed-oxides. $\mathrm{Pb}_{1-0.04} \mathrm{Sm}_{0.02} \mathrm{Nd}_{0.02}\left[\left(\mathrm{Zr}_{0.55}, \mathrm{Ti}_{0.45}\right)_{1-2 \mathrm{x}}, \mathrm{x}\left(\mathrm{Y}_{2 / 3}, \mathrm{Mo}_{1 / 3}\right), \mathrm{x}\left(\mathrm{Y}_{2 / 3}, \mathrm{Ni}_{1 / 3}\right)\right] \mathrm{O}_{3}$ such that $(\mathrm{x}=0.01,0.03,0.05,0.07$ and 0.1$)$, are studied. All the samples were being sintered at a temperature ranging from $1100^{\circ} \mathrm{C}$ to $1180^{\circ} \mathrm{C}$ after being compacted in circular discs. The detailed structure was carried out for sintered specimens. The results of X-ray diffraction showed that all the ceramics specimens have a perovskite phase. The phase structure of $\mathrm{Pb}_{1-0.04} \mathrm{Sm}_{0.02} \mathrm{Nd}_{0.02}\left[\left(\mathrm{Zr}_{0.55}, \mathrm{Ti}_{0.45}\right)_{1-2 \mathrm{x}}\right.$, $\left.\mathrm{x}\left(\mathrm{Y}_{2 / 3}, \mathrm{Mo}_{1 / 3}\right), \mathrm{x}\left(\mathrm{Y}_{2 / 3}, \mathrm{Ni}_{1 / 3}\right)\right] \mathrm{O}_{3}$ ceramics was transformed from the tetragonal to the rhombohedral, with an increase in the ratio of $\mathrm{Zr} / \mathrm{Ti}$ in system. The scanning Electron Microscopy (SEM) showed an increase of the mean grain size when the sintering temperature was increased. The lattice parameter measurements showed that tetragonal and rhombohedral unit cells of the phases depend on the sintering temperature.
\end{abstract}

Keywords: Sintering; X-Ray Diffraction; Tetragonal; Rhombohedral; PZT Ceramic

\section{Introduction}

The ceramic-type lead zirconate titanate has been studied widely during the last decades [2,3]. PZT powders were prepared by the reaction process using oxides as starting materials. Barium titanate has long been known for its large dielectric constant [4]. Several suitable additives are used to improve and/or modify its properties: $\mathrm{Sr}$ to decrease the critical temperature $\mathrm{TC}\left(<120^{\circ} \mathrm{C}\right)$, to increase $\mathrm{Pb}$ [4], $\mathrm{Ce}$ and $\mathrm{Nb}$ to increase the dielectric constant and the spontaneous polarization [5]. In ceramic manufacturing technology, piezoelectric PZT ceramic compositions are most likely to be near the morphotropic phase boundary [1]. The electromechanical response of these ceramics is known to be most pronounced at the morphotropic phase boundary (MPB) composition which separates the tetragonal ( $\mathrm{Ti}$ rich) and rhombohedral ( $\mathrm{Zr}$ rich) phase fields. Despite extensive work on the location of the MPB, considerable controversy exists about the nature and exact composition range of the MPB [6,7].
We present in this work the preparation and the different stages of the formation reaction of the solid solution, reports the influence of sintering temperature on density and porosity. Then we will detail the different techniques of analysis applied to this compound, and we begin first by XRD and SEM. X-ray diffraction is presented to demonstrate the co-existence of the tetragonal and rhombohedral phases. Finally, we present some electrical properties: the dielectric constant and electrical loss angle for selected compositions of PZT prepared. These studies help us to accumulate as much information on these materials.

\section{Experimental}

The starting materials are carefully homogenized for three hours in the middle acetone into a beaker through a magnetic stirrer. Then dried in an oven at temperature $120^{\circ} \mathrm{C}$ for two hours, the powder is ground in a glass mortar to a particle size as fine as possible. After that, 
our mixtures are compacted in a mold as a pellet using a hand press. The pellets obtained are dried again at a temperature of about $50^{\circ} \mathrm{C}$ for 30 minutes. The sample is in the open air at temperatures ranging at $800^{\circ} \mathrm{C}$ in a programmable furnace brand " $\mathrm{L}$ Nabertherm 60 programmable" which can reach $1200^{\circ} \mathrm{C}$. The heating rate used $2^{\circ} \mathrm{C} / \mathrm{min}$ and the holding time is two hours, cooling material is slow. All compounds obtained were characterized by the diagrams obtained X-ray diffraction using a diffractometer D500. Five samples of the solid solution were prepared from a mixture of oxide whose rate purities are shown in Table 1.

\section{Sintering}

The basic technique for the preparation of ceramic parts is sintering, if the transformation, through the mechanisms of atomic diffusion, a powdery product-noncohesive granular medium, composed of loosely agglomerated particles [8]. In most cases, a smart operation is performed, whose aim is the removal of organic substances by calcination at low temperature. The smart is usually performed in a furnace different from that of sintering, the main reason being that it is difficult for even an oven jointly meets the constraints of thermal cycling and air that are different for these two operations. Bridges are established between the particles quickly and welded together, these bridges will give rise to grain boundaries, at which point the porosity remains high. The porosity is changing the pore radius decreases and increases the compactness; porosity takes the form of substantially spherical isolated pores, and there is a coarsening of crystals, the polycrystalline structure is beginning to emerge. The porosity control ceramics (volume fraction, size and pore geometry) allows to vary their properties and to obtain products with desirable characteristics (thermal and mechanical properties). It is necessary during the various manufacturing steps to control accurately the thermal cycle imposed on materials (heating rate,

Table 1. The matrix of each composition from A1 to A5.

\begin{tabular}{cc}
\hline & composition \\
\hline A1 & $\mathrm{Pb}_{1-0.04} \mathrm{Sm}_{0.02} \mathrm{Nd}_{0.02}\left[\left(\mathrm{Zr}_{0.55}, \mathrm{Ti}_{0.45}\right)_{1-0.02}, 0.01\left(\mathrm{Y}_{2 / 3}, \mathrm{Mo}_{1 / 3}\right)\right.$, \\
& $\left.0.01\left(\mathrm{Y}_{2 / 3}, \mathrm{Ni}_{1 / 3}\right)\right] \mathrm{O}_{3}$ \\
A2 & $\mathrm{Pb}_{1-0.04} \mathrm{Sm}_{0.02} \mathrm{Nd}_{0.02}\left[\left(\mathrm{Zr}_{0.55}, \mathrm{Ti}_{0.45}\right)_{1-0.06}, 0.03\left(\mathrm{Y}_{2 / 3}, \mathrm{Mo}_{1 / 3}\right)\right.$, \\
& $\left.0.03\left(\mathrm{Y}_{2 / 3}, \mathrm{Ni}_{1 / 3}\right)\right] \mathrm{O}_{3}$ \\
& $\mathrm{~Pb}_{1-0.04} \mathrm{Sm}_{0.02} \mathrm{Nd}_{0.02}\left[\left(\mathrm{Zr}_{0.55}, \mathrm{Ti}_{0.45}\right)_{1-0.1}, 0.05\left(\mathrm{Y}_{2 / 3}, \mathrm{Mo}_{1 / 3}\right)\right.$, \\
A3 & $\left.0.05\left(\mathrm{Y}_{2 / 3}, \mathrm{Ni}_{1 / 3}\right)\right] \mathrm{O}_{3}$ \\
& $\mathrm{~Pb}_{1-0.04} \mathrm{Sm}_{0.02} \mathrm{Nd}_{0.02}\left[\left(\mathrm{Zr}_{0.55}, \mathrm{Ti}_{0.45}\right)_{1-0.14}, 0.07\left(\mathrm{Y}_{2 / 3}, \mathrm{Mo}_{1 / 3}\right)\right.$, \\
& $\left.0.07\left(\mathrm{Y}_{2 / 3}, \mathrm{Ni}_{1 / 3}\right)\right] \mathrm{O}_{3}$ \\
& $\mathrm{~Pb}_{1-0.04} \mathrm{Sm}_{0.02} \mathrm{Nd}_{0.02}\left[\left(\mathrm{Zr}_{0.55}, \mathrm{Ti}_{0.45}\right)_{1-0.2}, 0.1\left(\mathrm{Y}_{2 / 3}, \mathrm{Mo}_{1 / 3}\right)\right.$, \\
& $\left.0.1\left(\mathrm{Y}_{2 / 3}, \mathrm{Ni}_{1 / 3}\right)\right] \mathrm{O}_{3}$ \\
\hline
\end{tabular}

holding time, sintering temperature and cooling rate) [9]. The present study is carried primarily on the five compositions, near the morphotropic phase boundary to determine some structural properties dielectric and mechanical.

\section{Results and Discussion}

\subsection{The Density}

The study of the density is necessary to optimize the optimum temperature sintering. Figure 1 shows the variation of density as a function of sintering temperature, it is seen that there is an increase in density up to 7.40 , so the optimum temperature of sintering is $1100^{\circ} \mathrm{C}$ for $\mathrm{A} 4$ and $\mathrm{A} 5$, but it was $1150^{\circ} \mathrm{C}$ for $\mathrm{A} 3$, finally it was $1180^{\circ} \mathrm{C}$ for $\mathrm{A} 1$ and A2. The quality of the material increases with increasing density and it increases with increasing the sintering temperature [10]. This may be explained by the effect of doping percentage, for A1 is $2 \%$ of dopant, for A2 it was $4 \%$. For A3 it was $10 \%$. For A4 it was $14 \%$. Finally for A5 it was $20 \%$. So it's quite different one regards every one of these compositions. The optimum temperature for sintering is influenced by several factors such as the addition of impurities, the rate of sintering, the holding time and also the composition of the protective atmosphere as it is achieved if this equilibrium is established [11]:

$$
\mathrm{PbO}-\mathrm{PbO}(\text { vapour }) \rightarrow \mathrm{Pb}(\text { Vapour })+\frac{1}{2} \mathrm{O}_{2}
$$

\subsection{The Porosity}

The porosity is calculated as follows:

$$
\begin{aligned}
& \mathrm{P}=1-\mathrm{d} \text {, where } \mathrm{d}=\mathrm{d}_{\text {exp }} / \mathrm{d}_{\mathrm{th}} \\
& \mathrm{d}_{\mathrm{th}} \text { : The theoretical density. } \\
& \mathrm{d}_{\text {exp }} \text { : experimental density. }
\end{aligned}
$$

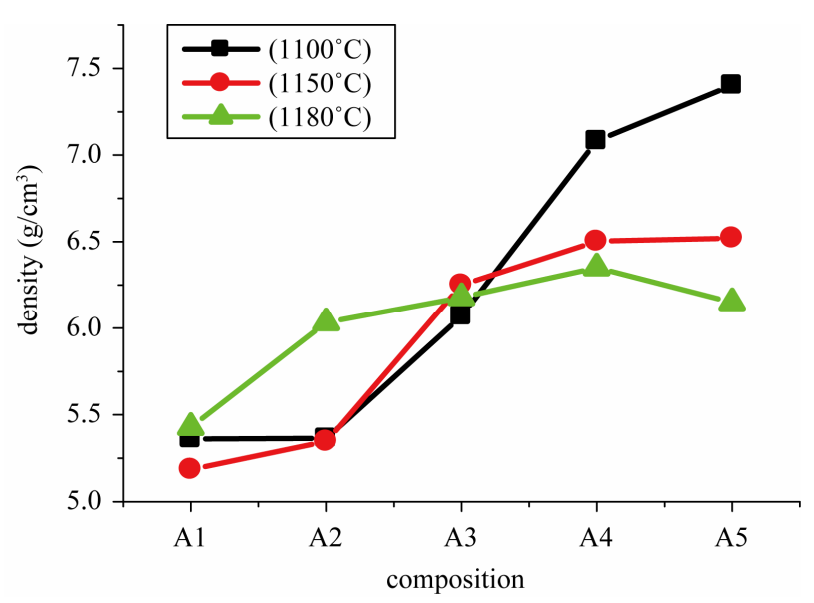

Figure 1. Versus of density with the sintering temperature. 
Figure 2 shows the variation of porosity with the sintering temperature. The porosity decreases when the sintering temperature increases to a minimum density which corresponds to the maximum.

\subsection{SEM Analysis}

Figure 3 shows scanning electron micrographs of the specimens sintered at $1100^{\circ} \mathrm{C}, 1150^{\circ} \mathrm{C}$ and $1180^{\circ} \mathrm{C}$ respectively. From these images, it can be deduced that the decrease of porosity with increasing sintering temperature, is due to a decrease in the number and size of the pores. Figure 4(a) describes the micro structural evolution. Grain size increases with increasing sintering temperature. A uniform microstructure was obtained at 1150 and $1180^{\circ} \mathrm{C}$. While the average grain size was $12-14 \mu \mathrm{m}$. This was caused by coexistence of the two phases in these materials. Figure 4(b) describes the microstructure evolution with the dopants percentage of the specimens sintered at $1150^{\circ} \mathrm{C}$. Grain size increases with increasing the dopants percentage.

\subsection{XRD Result}

Sintered powders were examined by X-ray diffractometry to ensure phase purity and to identify the phases and

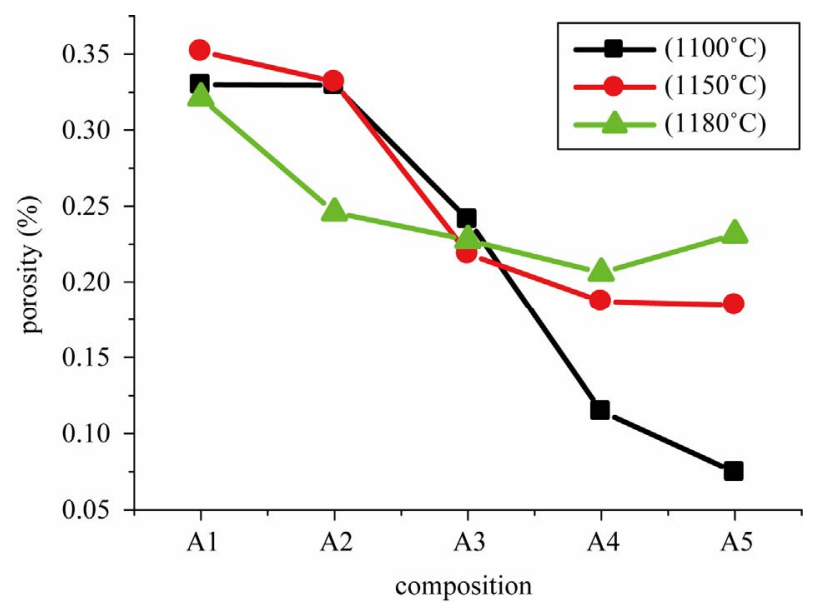

Figure 2. Versus of porosity with the sintering temperature.

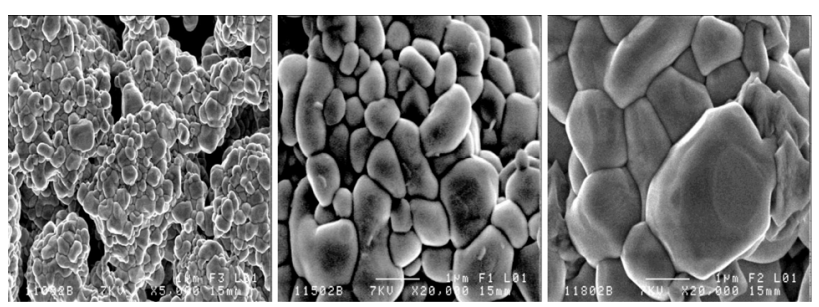

Figure 3. Scanning electron micrographs of polished and chemically etched of: $\mathrm{Pb}_{1-0.04} \mathrm{Sm}_{0.02} \mathrm{Nd}_{0.02}\left[\left(\mathrm{Zr}_{0.55}, \mathrm{Ti}_{0.45}\right)_{1-0.02}\right.$, $\left.0.01\left(\mathrm{Y}_{2 / 3}, \mathrm{Mo}_{1 / 3}\right), 0.01\left(\mathrm{Y}_{2 / 3}, \mathrm{Ni}_{1 / 3}\right)\right] \mathrm{O}_{3}$ sintered at $1100^{\circ} \mathrm{C}, 1150^{\circ} \mathrm{C}$ and $1180^{\circ} \mathrm{C}$ respectively from left to right.

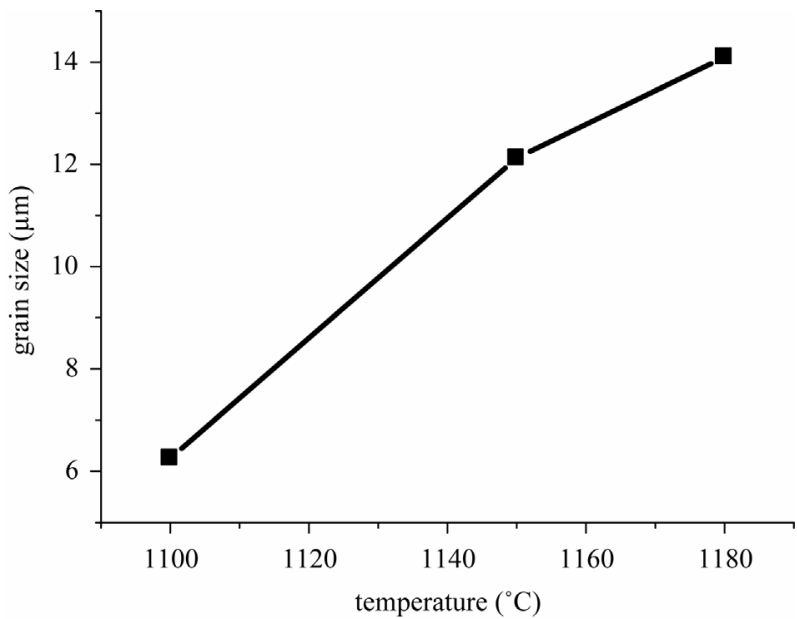

(a)

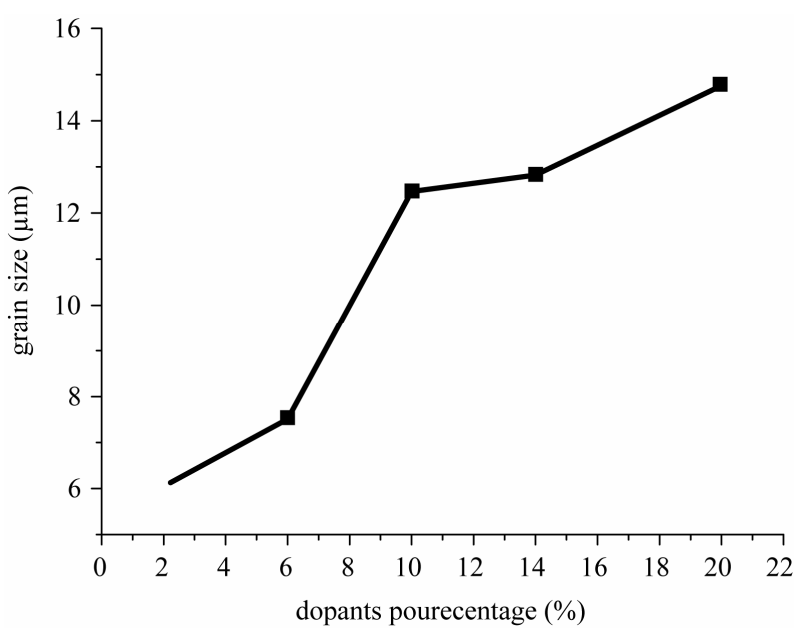

(b)

Figure 4. (a) Grain size versus sintering temperature; (b) Grain size evolution with the dopants percentage of the specimens sintered at $1150^{\circ} \mathrm{C}$.

lattice constants of the materials. The co-existence of tetragonal and rhombohedral phases near the mophotropic phase boundary implies the existence of compositional fluctuation. The compositional fluctuation can, in principle, be determined from the width of the X-ray diffraction peaks. A morphotropic phase boundary "co-existence region" was observed [shown by duplicated (200) peaks]. it has been reported in the literature that the splitting of these reflections into triplets takes place in conventionally-prepared ceramics due to compositional fluctuations leading to the co-existence of the tetragonal and rhombohedral phases $(T+R)$. The $X$-ray diffraction patterns of: $\mathrm{Pb}_{1-0.04} \mathrm{Sm}_{0.02} \mathrm{Nd}_{0.02}\left[\left(\mathrm{Zr}_{0.55}, \mathrm{Ti}_{0.45}\right)_{1-2 \mathrm{x}}, \mathrm{x}\left(\mathrm{Y}_{2 / 3}\right.\right.$, $\left.\left.\mathrm{Mo}_{1 / 3}\right), \mathrm{x}\left(\mathrm{Y}_{2 / 3}, \mathrm{Ni}_{1 / 3}\right)\right] \mathrm{O}_{3}$ materials $(\mathrm{x}=0.01,0.03,0.05$, 0.07 and 0.1 ), represented by samples A1, A2, A3, A4 and $\mathrm{A} 5$ are given in Figure 5. Triplet peaks around $2 \theta=$ $45^{\circ}$ indicate that the specimen consists of a mixture of 


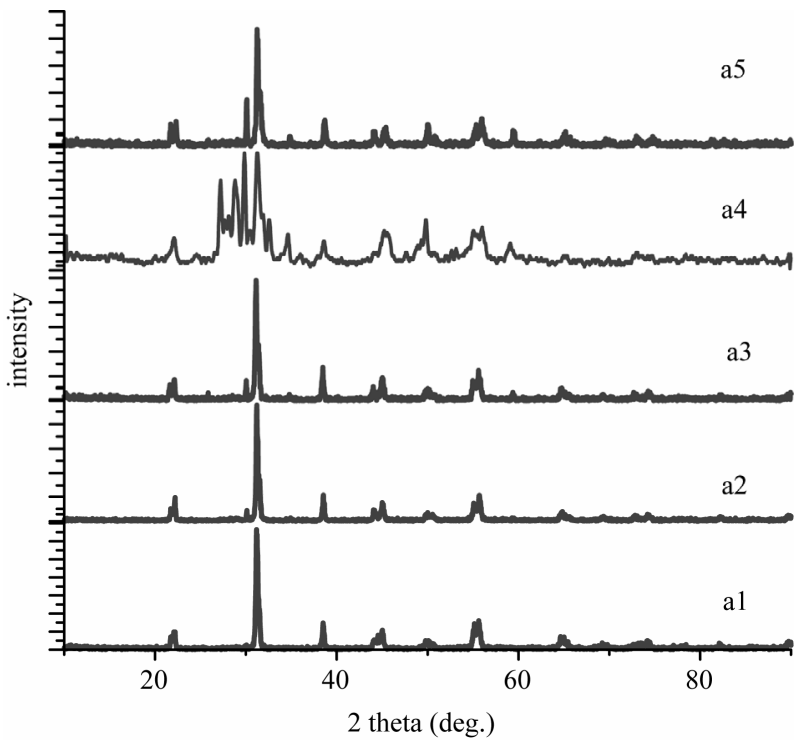

Figure 5. XRD patterns obtained by $\mathrm{Pb}_{1-0.04} \mathrm{Sm}_{0.02} \mathrm{Nd}_{0.02}$ $\left[\left(\mathrm{Zr}_{0.55}, \mathrm{Ti}_{0.45}\right)_{1-2 x}, \mathrm{x}\left(\mathrm{Y}_{2 / 3}, \mathrm{Mo}_{1 / 3}\right), \mathrm{x}\left(\mathrm{Y}_{2 / 3}, \mathrm{Ni}_{1 / 3}\right)\right] \mathrm{O}_{3}$ after crushing the pellets at $1150^{\circ} \mathrm{C}$ for $2 \mathrm{~h}$ : (a1) $\mathrm{x}=0.01$; (a2) $\mathrm{x}=0.03$; (a3) $\mathrm{x}=0.05$; (a4) $\mathrm{x}=0.07$; (a5) $\mathrm{x}=0.1$.

tetragonal and rhombohedral phases. It is shown that the tetragonal structure can be formed up to $\mathrm{x}_{\mathrm{T}}<44$. While the rhombohedral structure becomes stabilized for $\mathrm{x}_{\mathrm{R}}>$ 45 , however, at $x=44-45$ tetragonal and rhombohedral phases co-exist. The width $\Delta \mathrm{x}=\mathrm{x}_{\mathrm{T}}-\mathrm{x}_{\mathrm{R}}$ of the co-existence region from our work is close to that obtained by others [10-12]. The variation of the lattice parameters as a function of sintering temperature could be explained by the enhancement of cation diffusion and consequently by the homogenization of the micro composition. The variation in the lattice parameters of the identified phase composition shows that the values of the $\mathrm{c}_{\mathrm{T}} / \mathrm{a}_{\mathrm{T}}$ ratio have decreased. Figure 6 shows the lattice constant variations for the composition $\mathrm{Pb}_{1-0.04} \mathrm{Sm}_{0.02} \mathrm{Nd}_{0.02}\left[\left(\mathrm{Zr}_{0.55}, \mathrm{Ti}_{0.45}\right)_{1-0.02}\right.$, $\left.0.01\left(\mathrm{Y}_{2 / 3}, \mathrm{Mo}_{1 / 3}\right), 0.01\left(\mathrm{Y}_{2 / 3}, \mathrm{Ni}_{1 / 3}\right)\right] \mathrm{O}_{3}$ As a function of sintering temperature. This can be explained by microscopic compositional fluctuations occurring in these perovskite materials, which cannot provide a real homogeneity in the solid solutions, which determine the coexistence of tetragonal and rhombohedral phases [10].

\section{Conclusion}

The effect of sintering temperature on the density and grain size of ceramics has been investigated. It was demonstrated that the grain size increased continuously with sintering temperature. Increase of the porosity for temperature higher than the optimum can, therefore, be obtained to a greater rate evaporation of $\mathrm{PbO}$ compared to that recompensed. Microstructural studies of our materials obtained at different sintering in $1100^{\circ} \mathrm{C}, 1150^{\circ} \mathrm{C}$

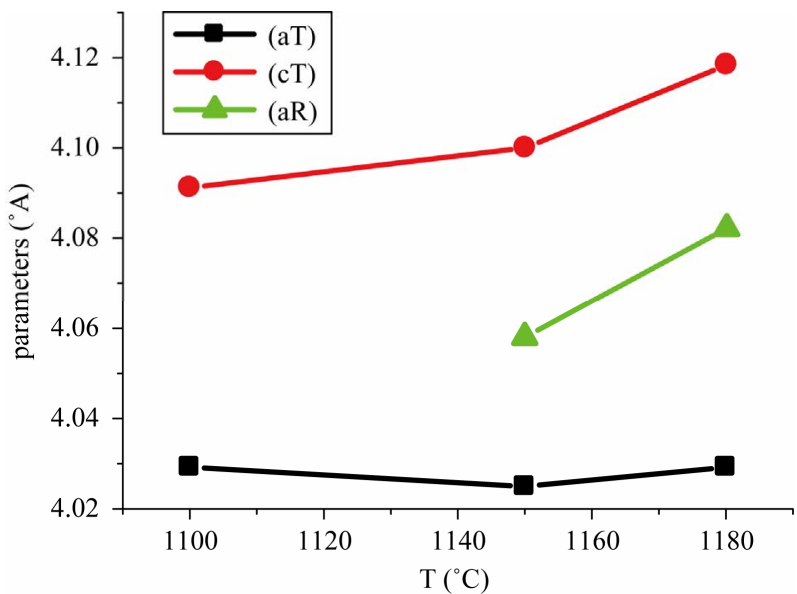

Figure 6. Lattice constant variations for both coexisting ferroelectric phases as a function of sintering temperature.

and $1180^{\circ} \mathrm{C}$, have shown the existence of the minimum porosity at a determined optimum sintering temperature. The phase of the sintered samples was examined by $\mathrm{X}$-ray diffractometry (XRD). In this work, the solid solution: $\quad \mathrm{Pb}_{1-0.04} \mathrm{Sm}_{0.02} \mathrm{Nd}_{0.02}\left(\mathrm{Zr}_{0.55}, \mathrm{Ti}_{0.45}\right)_{1-2 \mathrm{x}}, \mathrm{x}\left(\mathrm{Y}_{2 / 3}, \mathrm{Mo}_{1 / 3}\right)$, $\left.\mathrm{x}\left(\mathrm{Y}_{2 / 3}, \mathrm{Ni}_{1 / 3}\right)\right] \mathrm{O}_{3}(\mathrm{x}=0.01,0.03,0.05,0.07$ and 0.1$)$, is studied. The morphotropic phase boundary (MPB) of solid solution is located at $\mathrm{X}=0.07$. It was found that the MPB is not a narrow and vertically straight boundary but a region whose width depends on the firing temperature. The lattice parameters $\mathrm{a}_{\mathrm{T}}$ of the tetragonal structure and $a_{R}$ of the rhombohedral structure were found to vary with sintering temperature.

\section{REFERENCES}

[1] W. Qui and H. H. Hng, "Effect of Dopants on the Microstructure and Properties of PZT Ceramics," Materials Chemistry and Physics, Vol. 75, No. 1-3, 2002, pp. 151156.

[2] B. Jaffe, R. Cookjr and H. Jaffe, "Piezoelectric Ceramics," Academic Press, London and New York, 1971.

[3] A. Ballato, "Piezoelectricity: Old Effect, New Thrusts," IEEE Transactions on Ultrasonics, Ferroelectrics and Frequency Control, 1995, Vol. 42, No. 5, pp. 916-925. http://dx.doi.org/10.1109/58.464826

[4] G. H. Haertling, "Ferroelectric Ceramics: History and Technology," Journal of the American Ceramic Society, Vol. 82, No. 4, 1999, pp. 797-818. http://dx.doi.org/10.1111/j.1151-2916.1999.tb01840.x

[5] Z. Q. Zhuang, M. P. Harmer, et al., "The Effect of Octahedrally-Coordinated Calcium on the Ferroelectric Transition of $\mathrm{BaTiO}_{3}$," Materials Research Bulletin, Vol. 22, No. 10, 1987, pp. 1329-1335.

[6] K. Karl and K. H. Hardtl, "On the Origin of the Maximum in the Electromechanical Activity in $\mathrm{Pb}\left(\mathrm{Zr}_{\mathrm{x}} \mathrm{Ti}_{1-\mathrm{x}}\right) \mathrm{O}_{3}$ Ceramies near the Morphotropic Phase Boundary Ceramics 
near the Morphotropic Phase Boundary," Physica Status Solidi, Vol. 8, No. 1, 1971, pp. 87-98.

[7] P. Ari-Gur and L. Benguigui, "X-Ray Study of the PZT Solid Solutions near the Morphotropic Phase Transition," Solid State Communication, Vol. 15, No. 6, 1974, pp. 1077-1079. http://dx.doi.org/10.1016/0038-1098(74)90535-3

[8] P. Boche, "Ceramic Materials and Processes," Hermes Science Europe LTD., France, 2001, p. 55.

[9] J. M. Dorlot, J. P. Bailon and J. Masounave, "Materials," Edition of the Ecole Polytechnique of Montreal, Montreal, 1992.

[10] A. Boutarfaia, "Investigation of Co-Existence Region in
Lead Zirconate-Titanate Solid Solutions: X-Ray Diffraction Studies," Ceramic International, Vol. 26, No. 6, 2000, pp. 583-587.

http://dx.doi.org/10.1016/S0272-8842(99)00099-1

[11] R. B. Atkin and R. M. Fulrath, "Point Defects and Sintering of Lead Zirconate-Titanate," Journal of American Ceram Society, Vol. 54, No. 5, 1971, pp. 265-270. http://dx.doi.org/10.1111/j.1151-2916.1971.tb12286.x

[12] A. Boutarfaia, C. Boudaren, A. Mousser and S. E. Bouaoud, "Study of Phase Transition Line of PZT Ceramics by X-Ray Diffraction," Ceramics International, Vol. 21, No. 6, 1995, pp. 391-394. 